\title{
INFLUENCE OF Fe AND Si ADDITION ON THE PROPERTIES AND STRUCTURE CONDUCTIVITY ALUMINIUM
}

The effect of iron and silicon addition on the structure and properties of aluminium wire rod obtained in the laboratory horizontal direct chill casting process has been analysed. In addition, the impact of laboratory wire drawing process has been examined. The addition of iron and velocity of casting increase the strength of aluminium wire rod in as-cast condition while the electrical conductivity drop acceptable. Moreover, the laboratory wire drawing process causes work-hardening wires and increase drawing tension as a result of fragmentation of structure and growth of grain boundaries. It has been shown that iron is beneficial for mechanical and technological properties of aluminium.

Keywords: Al-Fe-Si alloy, horizontal direct chill casting, wire drawing process, electrical conductivity

\section{Introduction}

Pure aluminium and aluminium alloys are a very important materials because of its low density, excellent mechanical and electrical properties, good corrosion resistance and prices. Aluminium metal is alloyed with many elements like $\mathrm{Cu}, \mathrm{Mn}$, $\mathrm{Mg}, \mathrm{Si}, \mathrm{Zn}, \mathrm{Fe}$ etc., and it is used in transport, buildings and construction, packing, engineering and cables [1]. The main impurities in the technically pure aluminium is iron and silicon, as a residue in metallurgical processes for preparing $\mathrm{Al}_{2} \mathrm{O}_{3}$. Furthermore all commercial wrought aluminium alloys contain at least some iron and silicon, whose growing concentration is caused by an increasing use of recycled aluminium in manufacturing [2]. The advantage of the introduction of the iron to aluminium is: improving the mechanical properties and plasticity wires reducing the number of breaks during the drawing, the use of iron as an impurity occurring after refining bauxite ore to the chemical composition of the wires and low solubility $\mathrm{Fe}$ in $\mathrm{Al}$ didn't significantly affect the decrease in electrical conductivity. An additional benefit is the binding of iron with silicon which eliminates the clusters in the casting, thus causing the stress concentrators surface and microcracks in the wire drawing process.

Many studies have been conducted on the microstructures of rapidly solidified Al-Fe-Si alloys [3-6]. Depending on the casting conditions, chemical composition and the presence of trace elements we can obtained a different structure and properties of materials. The solid solubility of $\mathrm{Fe}$ in $\mathrm{Al}$ matrix is very low $\left(0.05 \%\right.$ at $\left.650^{\circ} \mathrm{C}\right)$, and $\mathrm{Fe}$ is mostly combined with $\mathrm{Al}$ and $\mathrm{Si}$ to form secondary intermetallic phases such as $\mathrm{Al}_{13} \mathrm{Fe}_{4}$ (sometimes referred to as $\left.\mathrm{Al}_{3} \mathrm{Fe}\right), \mathrm{Al}_{6} \mathrm{Fe}, \mathrm{Al}_{\mathrm{m}} \mathrm{Fe}, \alpha$-AlFeSi $\left(\mathrm{Al}_{8} \mathrm{Fe}{ }_{2} \mathrm{Si}\right)$, $\beta$-AlFeSi $\left(\mathrm{Al}_{5} \mathrm{FeSi}\right)$ and other [7-9]. In addition, the presence of other trace elements can also influence the phase evolution significantly $[10,11]$.

\section{Experimental methods}

The material used for testing was obtained in a laboratory direct chill casting process using graphite crystallizer. The input to the process of laboratory casting was aluminium scrap with known chemical composition. The first step was to conduct a continuous casting operation at different speeds, resulting obtained three ingots a round shape. The cast rods were drawing to the wire with a diameter of $3.0 \mathrm{~mm}$. The picture of the direct chill casting machine has been shown on Fig. 1.

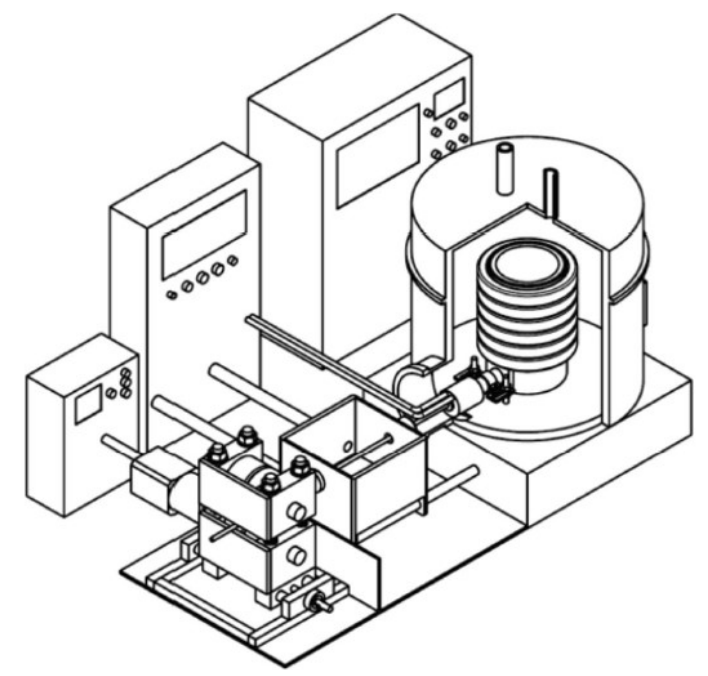

Fig. 1. The view of direct chill casting device

\footnotetext{
AGH UNIVERSITY OF SCIENCE AND TECHNOLOGY, FACULTY OF NON-FERROUS METALS, AL. MICKIEWICZA 30, 30-059 KRAKÓW, POLAND

Corresponding author: jablonsk@agh.edu.pl
} 
The device is equipped with an induction furnace, which allows to melt about $30 \mathrm{~kg}$ of aluminium in $30 \mathrm{~min}$. The melting process took place in a protective atmosphere of argon. The furnace is equipped with a power supply guarantees $20 \mathrm{~kW}$. The furnace is equipped with a horizontal crystallization system of primary and secondary cooling. Diameter cast rod was $14 \mathrm{~mm}$. All parameters of direct chill casting process described in Table 1.

TABLE 1

Parameters of direct chill casting process

\begin{tabular}{|c|c|c|c|}
\hline Alloys & $\begin{array}{l}\text { AlFe0.5Si0.2 } \\
\text { (I) }\end{array}$ & \begin{tabular}{|c|}
$\begin{array}{c}\text { AlFe0.8Si0.2 } \\
\text { (II) }\end{array}$ \\
\end{tabular} & \begin{tabular}{|l} 
AlFe0.8Si0.2 \\
(III)
\end{tabular} \\
\hline Casting velocity $[\mathrm{mm} / \mathrm{s}]$ & 1 & 1 & 2 \\
\hline $\begin{array}{l}\text { Temperature of liquid } \\
\text { metal }\left[{ }^{\circ} \mathrm{C}\right]\end{array}$ & 850 & 850 & 860 \\
\hline $\begin{array}{l}\text { Temperature of metal } \\
\text { (primary cooling) }\left[{ }^{\circ} \mathrm{C}\right]\end{array}$ & 180 & 178 & 181 \\
\hline $\begin{array}{l}\text { Temperature of metal } \\
\text { (secondary cooling) }\left[{ }^{\circ} \mathrm{C}\right]\end{array}$ & 35 & 33 & 35 \\
\hline $\begin{array}{l}\text { Temperature of primary } \\
\text { cooling water }\left[{ }^{\circ} \mathrm{C}\right]\end{array}$ & \multicolumn{3}{|c|}{5} \\
\hline $\begin{array}{l}\text { Temperature of seconda- } \\
\text { ry cooling water }\left[{ }^{\circ} \mathrm{C}\right]\end{array}$ & \multicolumn{3}{|c|}{8} \\
\hline $\begin{array}{l}\text { Velocity of primary co- } \\
\text { oling water }[1 / \mathrm{min}]\end{array}$ & \multicolumn{3}{|c|}{0,5} \\
\hline $\begin{array}{l}\text { Velocity of secondary } \\
\text { cooling water [1/min] }\end{array}$ & \multicolumn{3}{|c|}{0,3} \\
\hline $\begin{array}{l}\text { Time of melting alumi- } \\
\text { nium alloy [min] }\end{array}$ & \multicolumn{3}{|c|}{60} \\
\hline Diameter of ingot [mm] & \multicolumn{3}{|c|}{14} \\
\hline
\end{tabular}

\section{Results and discussion}

Chemical composition of ingots were carried out on the optical emission spectrometer (OES) and show uniform distribution of cast iron for the three bars (Table 2).
TABLE 2

Chemical composition of ingots casting with different velocity

\begin{tabular}{|c|c|c|c|}
\hline Materials & AlFe0.5Si0.2 (I) & AlFe0.8Si0.2 (II) & AlFe0.8Si0.2 (III) \\
\hline$v^{*}[\mathrm{~mm} / \mathrm{s}]$ & 1 & 1 & 2 \\
\hline Al & 99,251 & 98,889 & 98,911 \\
\hline Si & 0,211 & 0,206 & 0,207 \\
\hline $\mathbf{F e}$ & 0,492 & 0,858 & 0,839 \\
\hline Others** & 0,046 & 0,047 & 0,044 \\
\hline
\end{tabular}

Depending on the process conditions of casting followed by the structure and properties of ingots. Lower iron content and low speed causes a large crystallites (Fig. 2a). The sample with the increase iron content and casting velocity causes fragmentation of the macrostructure of cast rods and change the orientation of crystallites with longitudinal to perpendicular to the surface of the ingot in the direction of heat dissipation to the environment (Fig. 2b,c). Moreover, on the pictures of cross-section ingots we can see the presence of frozen crystals zone outside the cast ingots characteristic of the applied cooling system.

Wire drawing process causes the fragmentation of the structure and elongation of grains in the direction of plasticity flow (Fig. 3). The increase of strain influence the mechanical and electrical properties of the wires.

Microstructure observation using optical microscopy reveals existing phase Al-Fe-Si which is present as grain boundary. The limited solubility of iron in aluminium is $0.05 \%$ by weight at $650^{\circ} \mathrm{C}$ and drastically decrease with a drop of temperature, so the iron is combined with silicon and forms phases $\alpha$-AlFeSi, which is most often occurs when the amount of additional alloying elements is low. The growth in the casting velocity increase the occurrence of eutectic consisting of a solid solution ironaluminium-silicon (Fig. 4).

The deformation in the drawing process makes distribution of precipitates in the form of longitudinal lines arming material a)

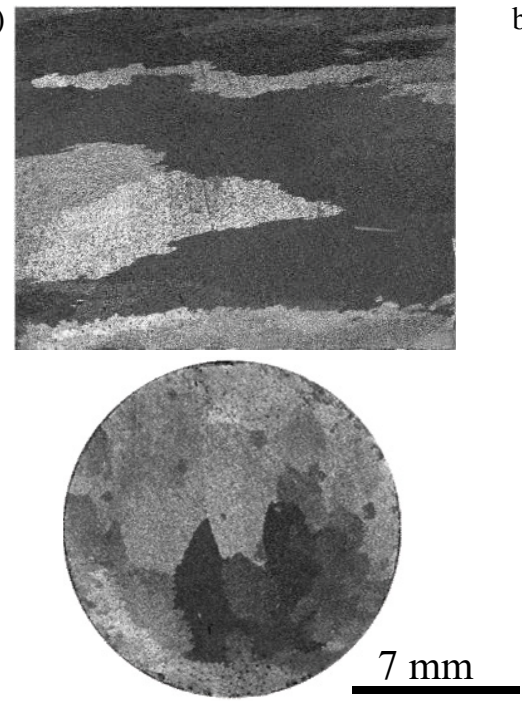

b)

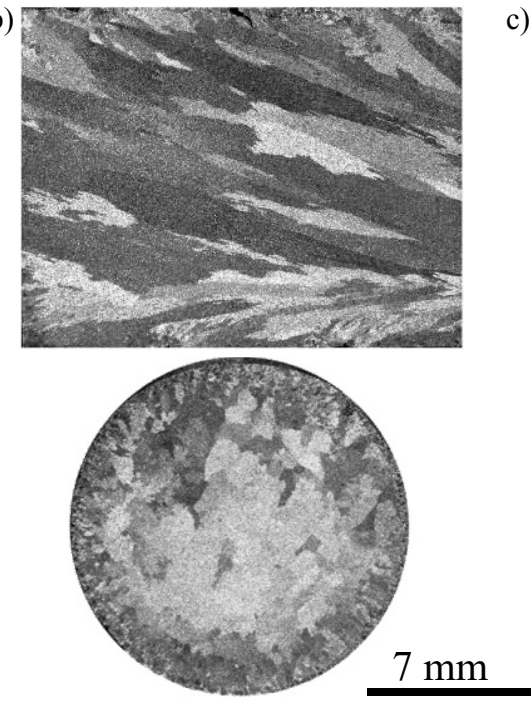

c)

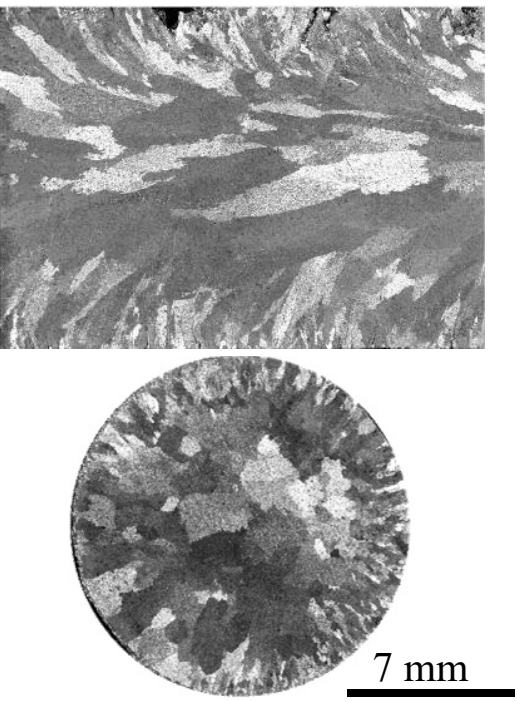

Fig. 2. Stereoscopy observation ( $3 \times$ magnification) of longitudinal (row at the top) and transverse (row at the bottom) macrostructure of ingots cast on the left direction of $14 \mathrm{~mm}$ diameter: a) $\mathrm{AlFe} 0.5 \mathrm{Si0} .2$ (I); b) AlFe0.8Si0.2 (II) and c) AlFe0.8Si0.2 (III) 
a)

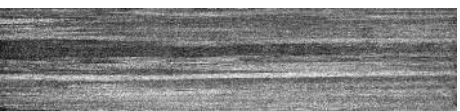

$3 \mathrm{~mm}$ b)

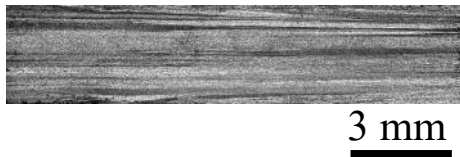

c)

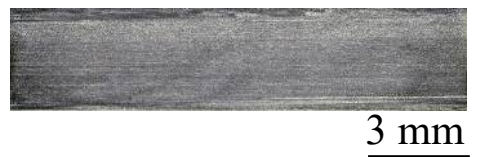

Fig. 3. Stereoscopy observation ( $3 \times$ magnification) of longitudinal macrostructure of wires $3,0 \mathrm{~mm}$ diameter: a) AlFe $0.5 \mathrm{Si} 0.2$ (I); b) AlFe $0.8 \mathrm{Si} 0.2$ (II) and c) $\mathrm{AlFe} 0.8 \mathrm{Si0} 0.2$ (III)
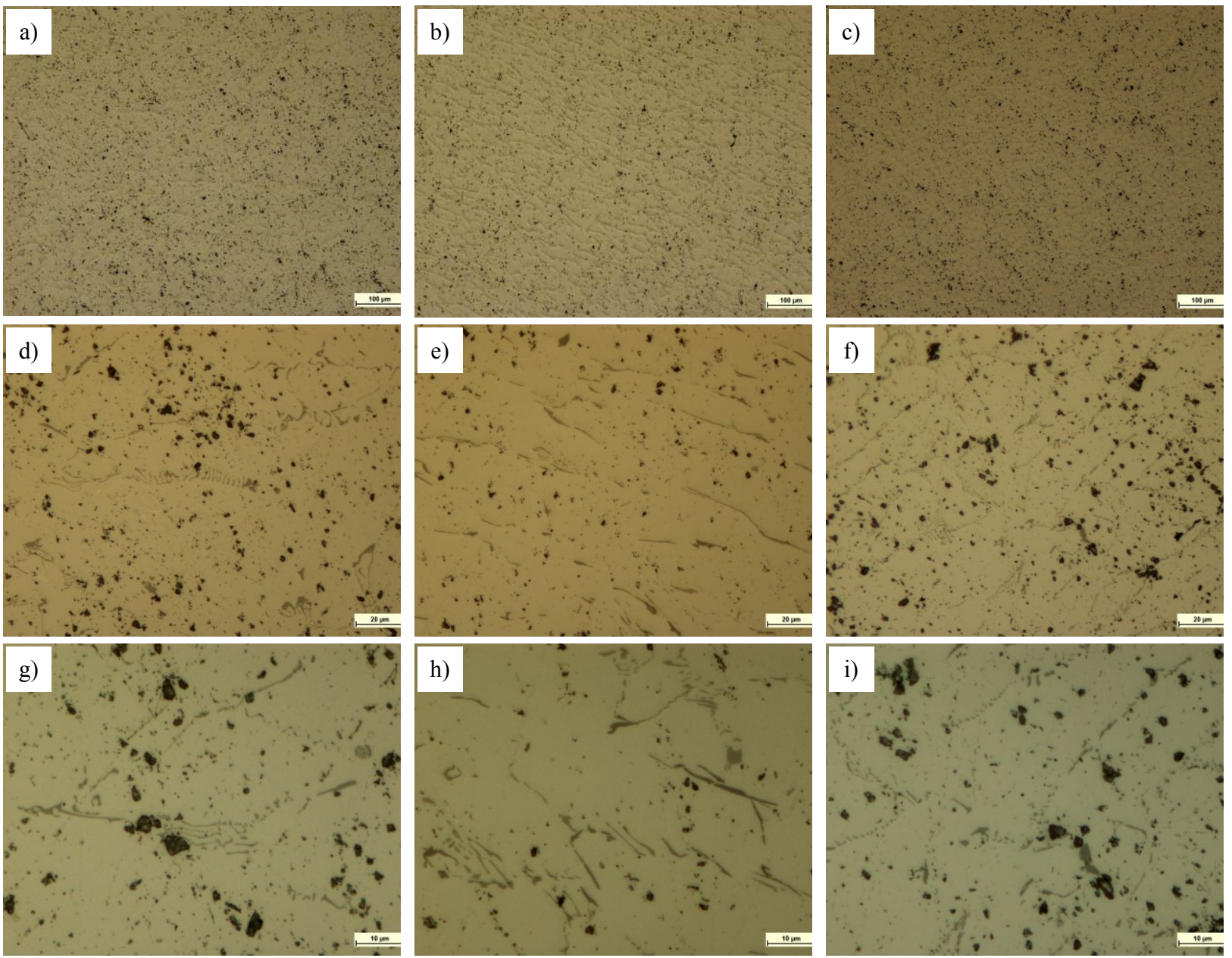

Fig. 4. Longitudinal microstructure of rods $14 \mathrm{~mm}$ diameter: AlFe0.5Si0.2 (I) - a,d,g; AlFe0.8Si0.2 (II) - b,e,h and AlFe0.8Si0.2 (III) - c,f,i in different magnification

(Fig. 5). Greater quantity of phases occurs at larger volumes of alloying elements.

Microstructures observed with using secondary electron (SE) show the presence of iron and silicon phases at grain boundaries in the form of zebra or Chinese writing (Fig. 6a,c). Cold deformation during wire drawing process caused breaking the phase and change its orientation in the direction of the material flow (Fig. 6b,d). The EDS analysis revealed the presence of stable $\mathrm{Al}_{3} \mathrm{Fe}$ and $\mathrm{Al}_{8} \mathrm{Fe}_{2} \mathrm{Si}$ phases (Fig. 7).

The structural changes are reflected in the properties of materials. Due to the use of material for electricity properties so decided to measure drawing force and electrical resistivity. Cold drawing process was conducted using round conical dies made of cemented carbide (angle of wire die was $18^{\circ}$ ). The drawing force decrease during real strain because it's a reduction of cross-section and the drawing tension increasing due to the strengthening of the materials during wire drawing process (Fig. 8). The growth of iron addition (sample II) and casting velocity (sample III) increase drawing tension and force.

Each defect provides an additional increase of electrical resistivity of metallic materials according to the well-known Matthiessen's rule. The total electrical resistance is the sum of thermal vibrations, impurities and lattice defects. The lattice defects consist of several parts, such solute atoms dissolved in the matrix, precipitates, dislocations and grain boundaries [12].

The electrical resistance was measured on the high-precision inspection and test unit (resistomat). The growth of iron addition (sample II) and casting velocity (sample III) increase electrical resistivity but the highest growth is observed at the beginning of the deformation because it has the highest work hardening of materials (Fig. 9). Further strain doesn't increase the 


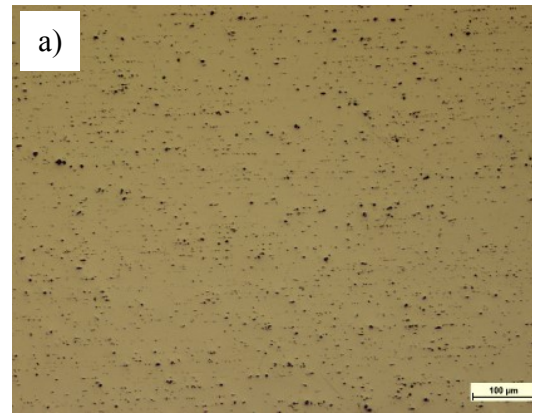

\section{b)}

c)
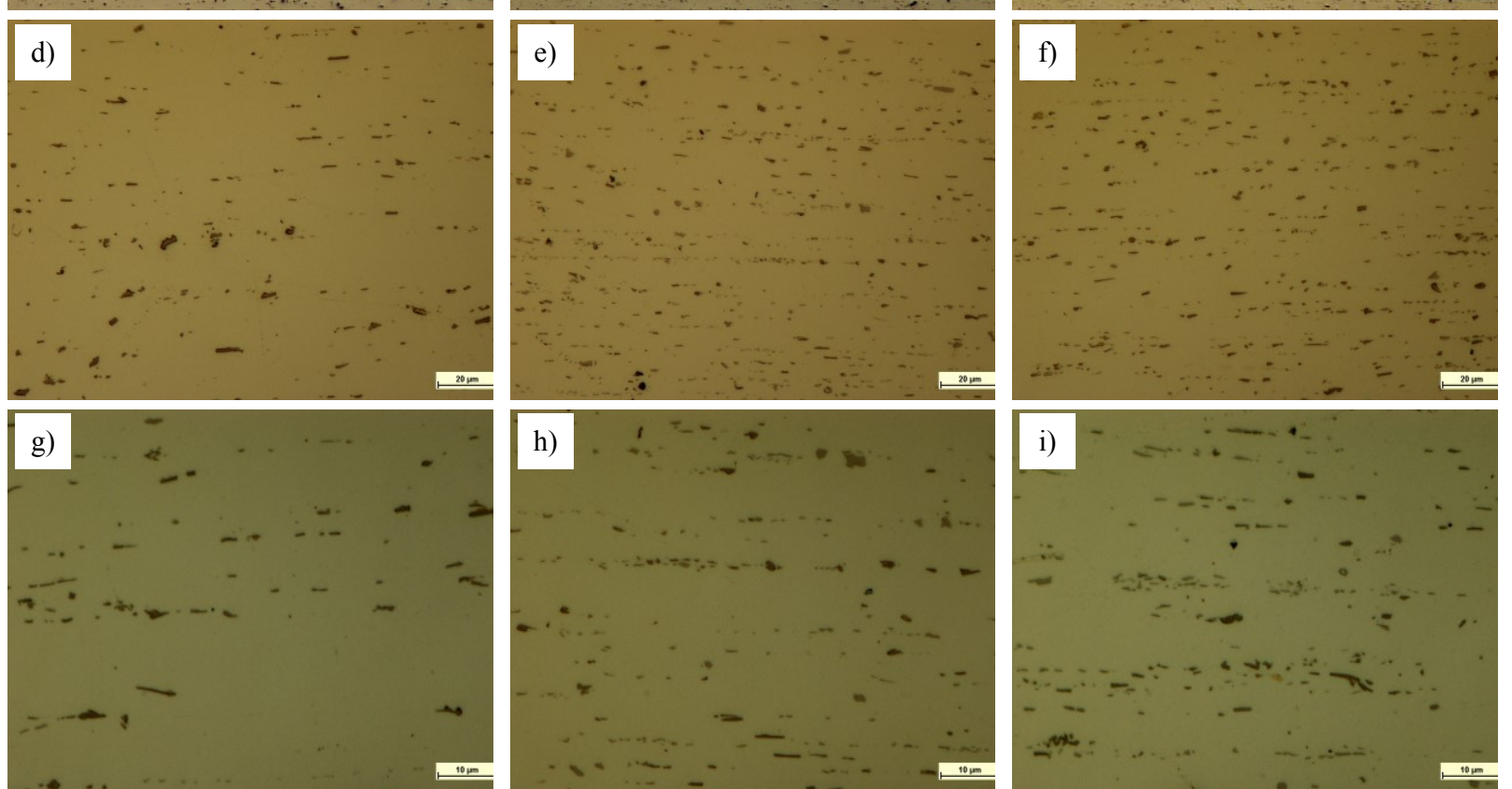

Fig. 5. Longitudinal microstructure of wires $3 \mathrm{~mm}$ diameter: $\mathrm{AlFe} 0.5 \mathrm{Si} 0.2$ (I) - a,d,g; $\mathrm{AlFe} 0.8 \mathrm{Si} 0.2$ (II) - b,e,h and AlFe0.8Si0.2 (III) - c,f,i in different magnification
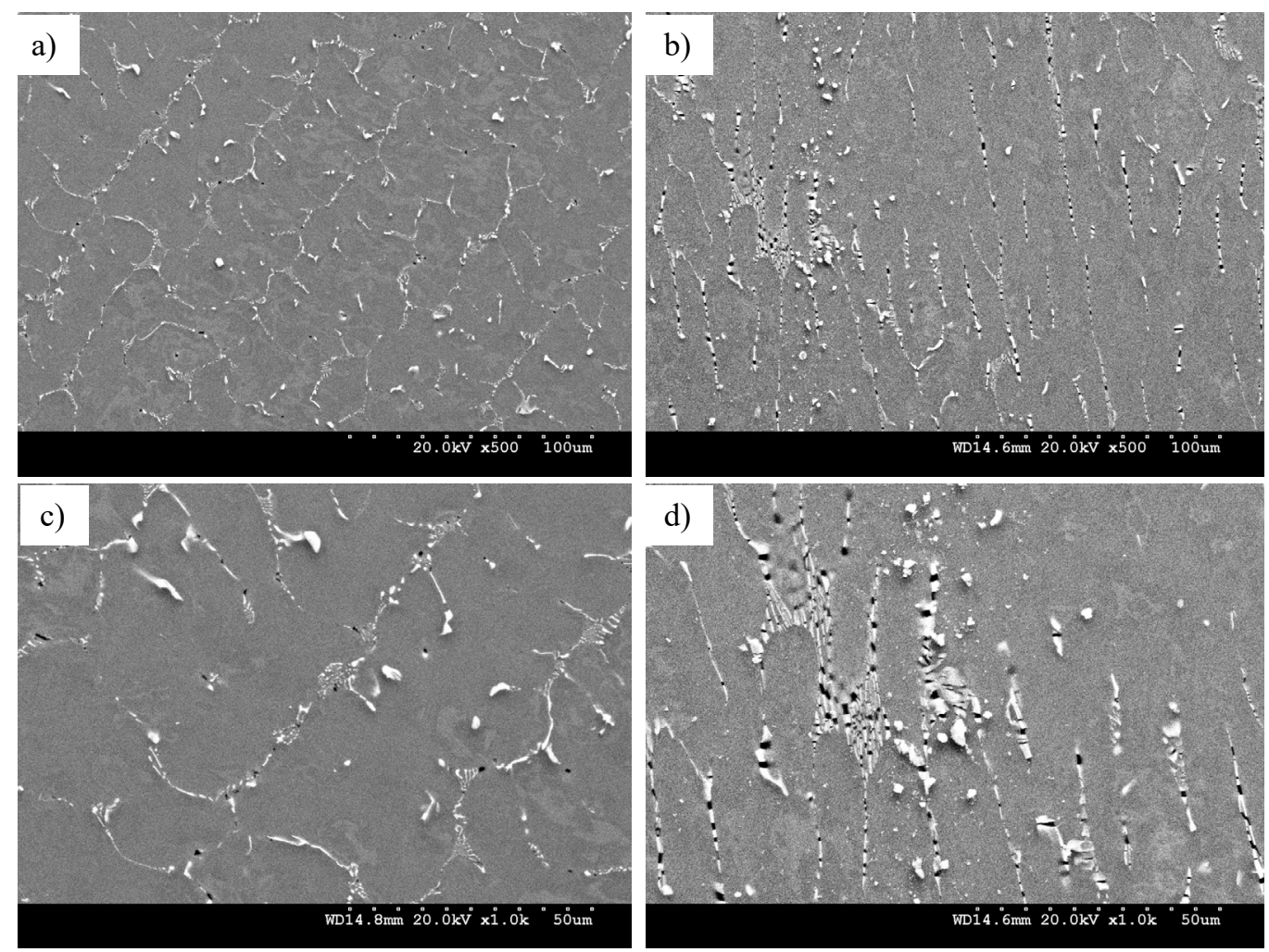

Fig. 6. Longitudinal microstructure (SEM) of rod $(a, c)$ and wire (b, d) of AlFe $0.5 \mathrm{Si} 0.2$ (I) in different magnification 

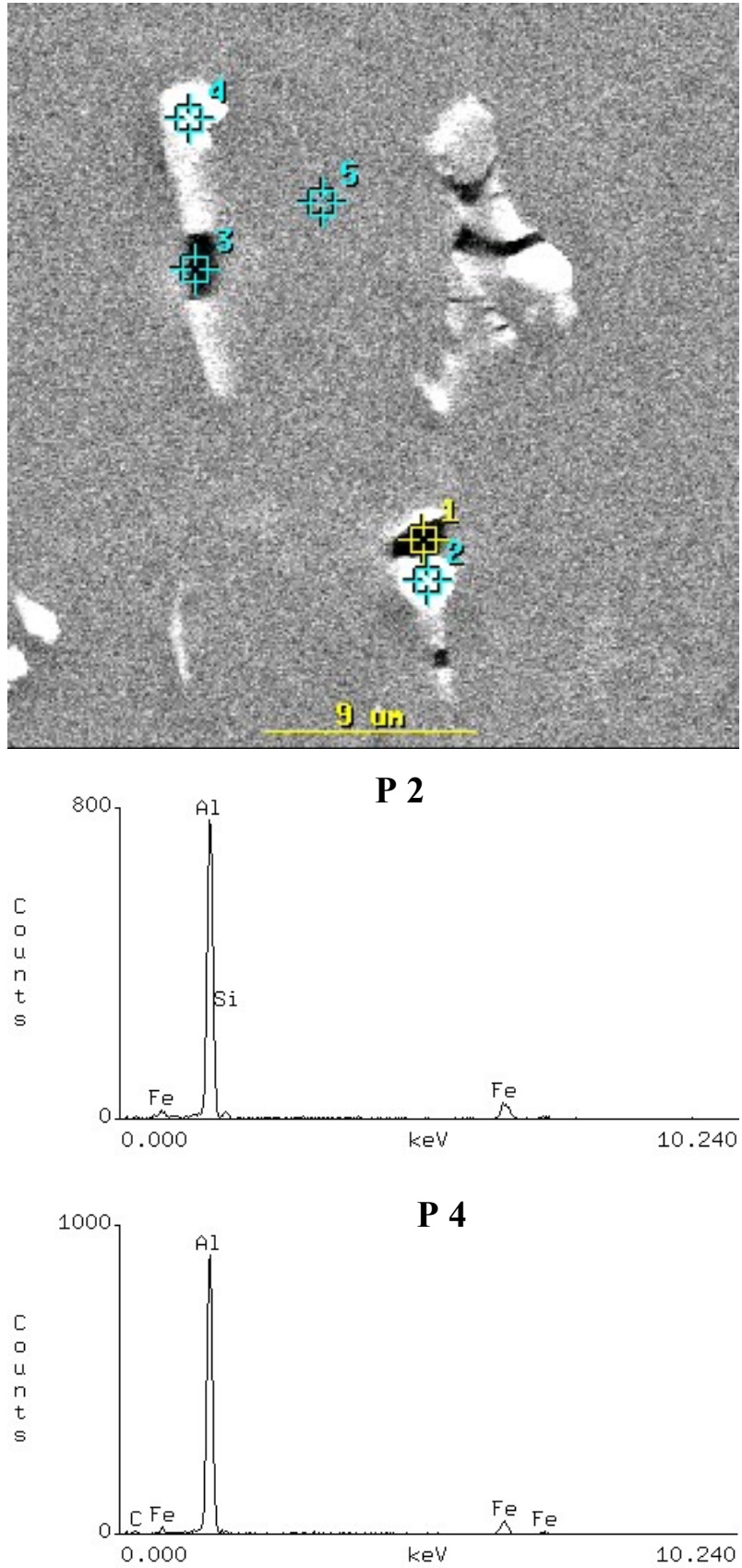

Fig. 7. EDS analysis of $\mathrm{AlSi} 0,2 \mathrm{Fe} 0,5$ (I) rod

electrical resistivity. The difference between materials (sample I) due to the iron addition, which strongly increases resistivity (sample II) and further increase in resistivity is observed as a result of fragmentation of the structure due to an rise of casting velocity (sample III). We observed a significant decrease in electrical properties of the $3 \mathrm{~mm}$ diameter wires as a result of terms of casting, deformation and additional alloying. For example according to IEC 60889 the resistivity at $20^{\circ} \mathrm{C}$ shall be not greater than $28.264 \mathrm{n} \Omega \mathrm{m}$ of aluminium wires in the diameter range $1.25 \mathrm{~mm}$ to $5.00 \mathrm{~mm}$.

Deformation during wire drawing process causes changes in mechanical properties. There has been an increase ultimate tensile strength and yield stress and decrease elongation at rapture (Fig. 10). For the three tested materials we can see dif-
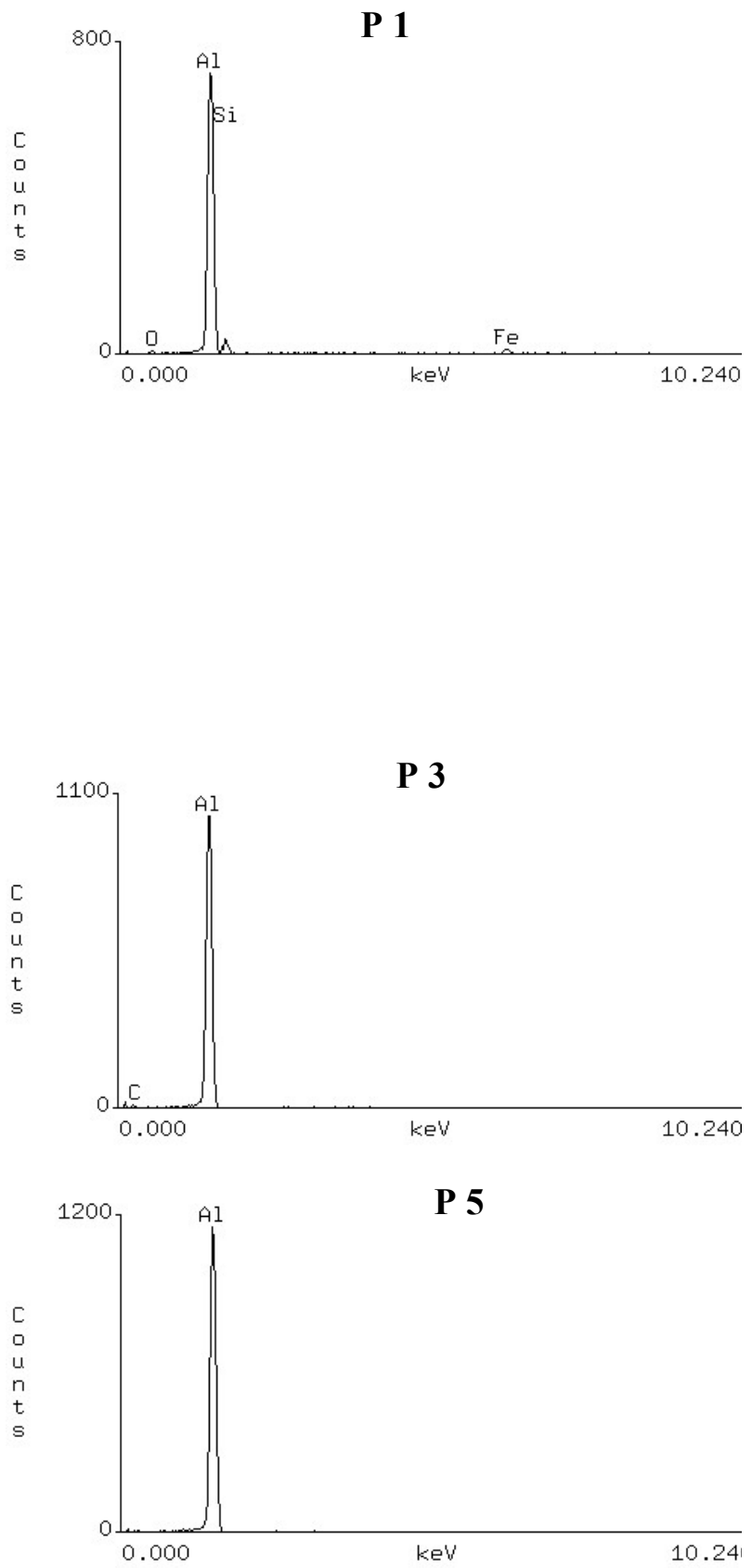

ferent levels of properties for casting. The highest of u.t.s. and y.s. have aluminium with $0,8 \mathrm{Fe}$ weight $\%$ addition regardless of the casting velocity. Iron addition is present in the form of foreign phases in aluminium and armed Al making a composite. Wire drawing process causes work hardening of materials and elongation of grains in direction of plastic flow.

\section{Conclusions}

The aim of this work was to determinate the influence of casting terms, and iron and silicon addition to aluminium on the mechanical and electrical properties. The materials used to wire to overhead wire conductor should have good compression 


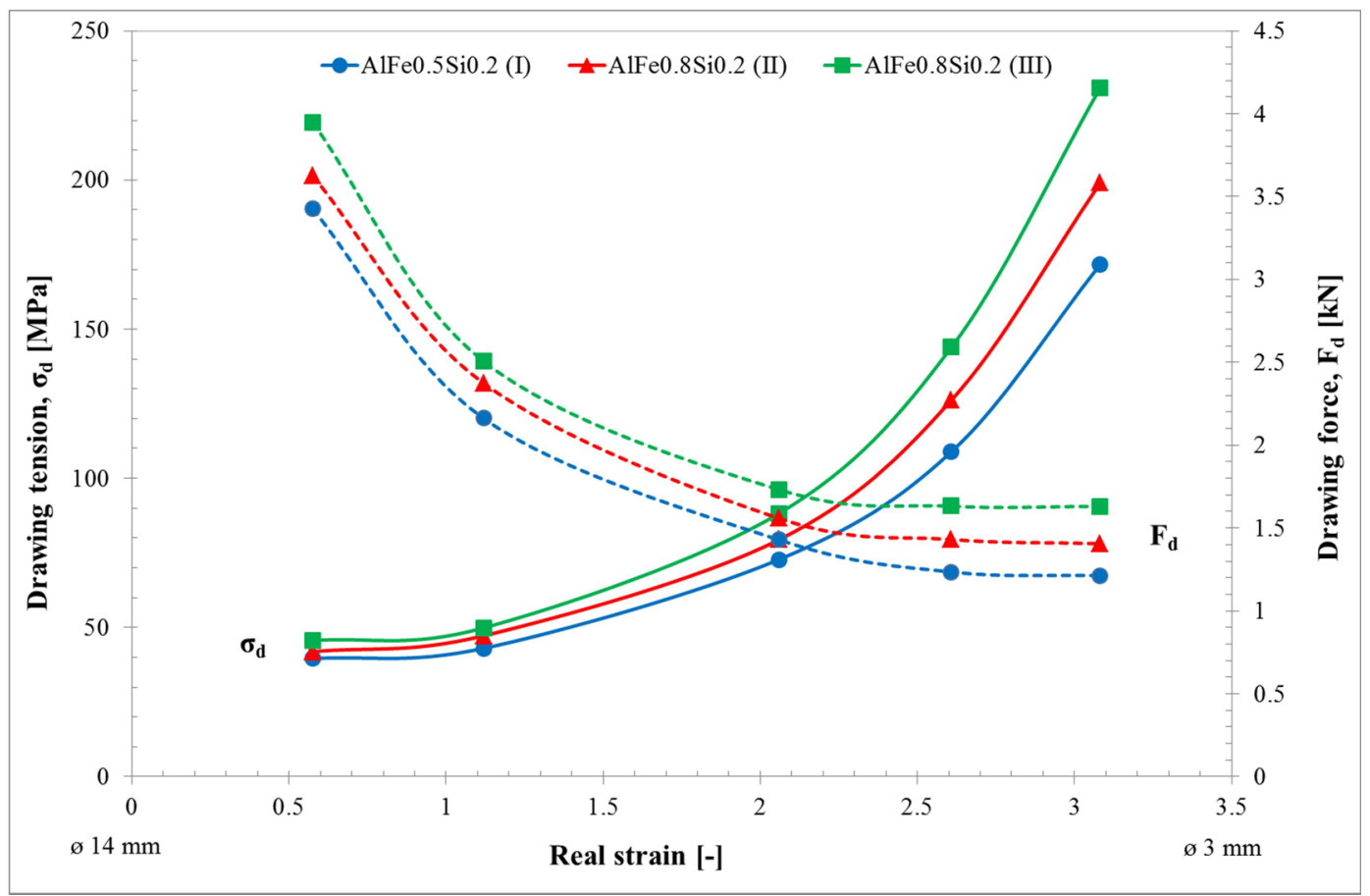

Fig. 8. The graph of drawing tension and drawing force in function of real strain for Al-Fe-Si

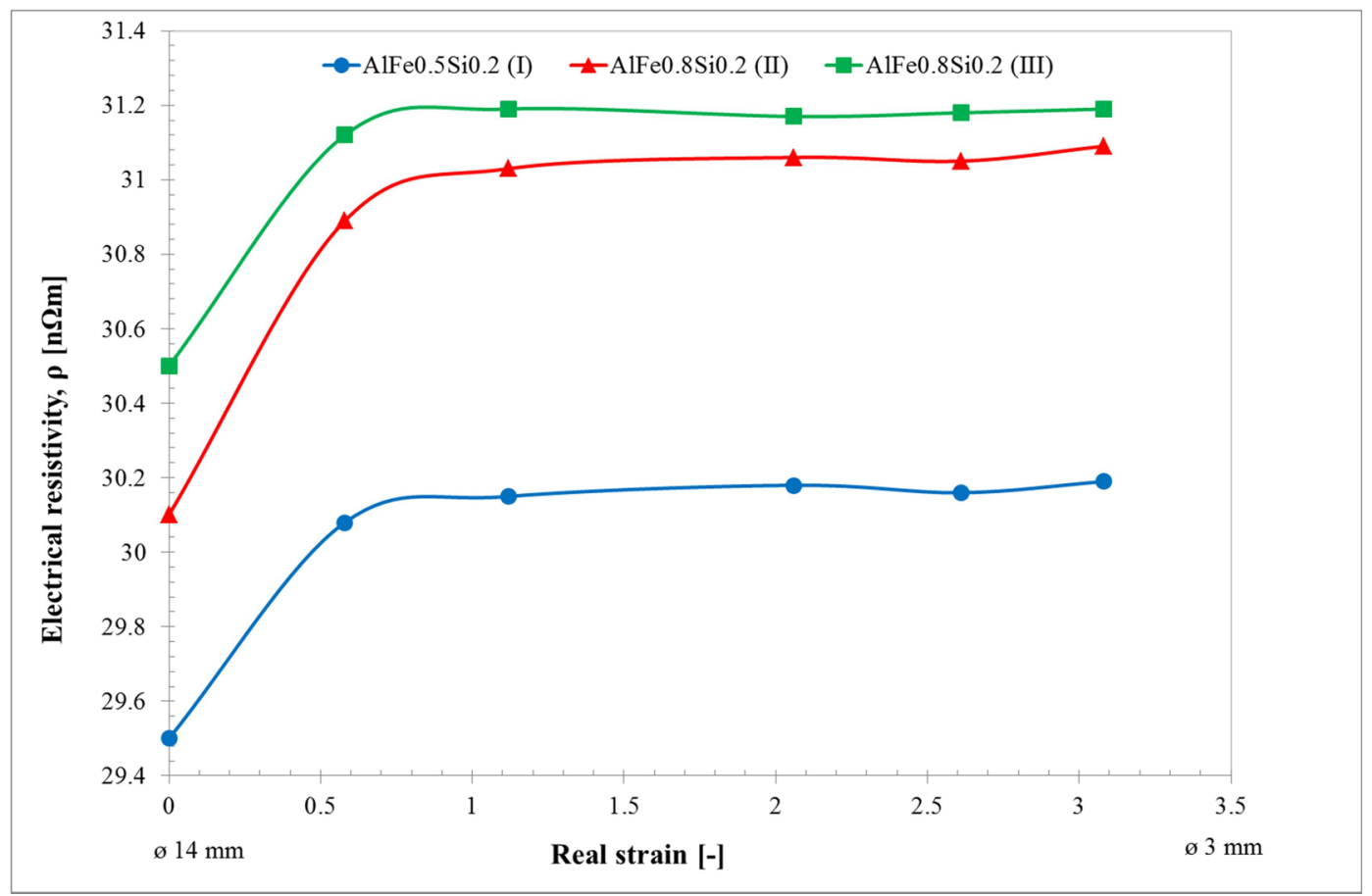

Fig. 9. The graph of electrical resistivity in function of real strain for Al-Si-Fe

between mechanical and electrical properties. On the basis of the results of research and analysis we can draw the following conclusions:

- Increase iron addition from 0,5 to 0,8 weight $\%$ in aluminium and increase velocity of casting causes fragmentation of structure aluminium rod and change crystallite from longitude to traverse of casting direction,

- Laboratory wire drawing process causes work hardening aluminium rod on account of rise dislocation, vacancy and fragmentation of structure (reducing the grain size and increase the grain boundaries) resulting in increased resistivity and ultimate tensile strength, yield strength and decrease elongation at fracture,

- In aluminium rod we observe the occurrence stable phase $\mathrm{Al}_{3} \mathrm{Fe}$ and $\alpha-\left(\mathrm{Al}_{8} \mathrm{Fe}_{2} \mathrm{Si}\right)$ which influence to structure and properties of wires. 


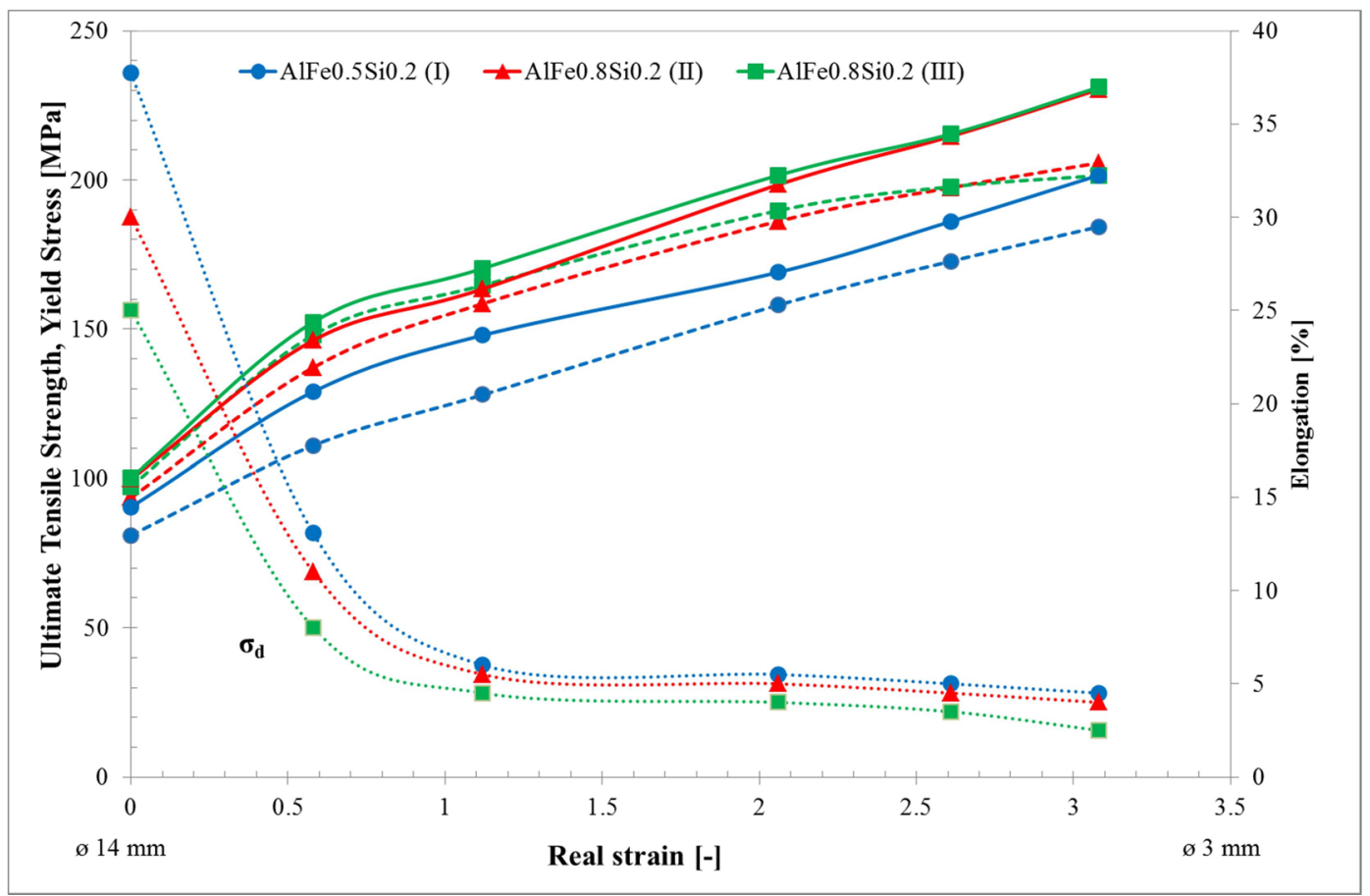

Fig. 10. The graph of mechanical properties in function of real strain for Al-Fe-Si (solid line-ultimate tensile strength, dashed line-yield stress, dotted line- elongation at rupture)

\section{Acknowledgements}

Research funded by the statutory work no. 11.11.180.004, Faculty of NonFerrous Metals of the AGH University of Science and Technology.

\section{REFERENCES}

[1] S.B. Hassan, V.-. Aigbodion, J. Alloys Compd. 486, 309-314 (2009).

[2] D.V. Malakhov, D. Panahi, M. Gallerneault, Calphad, 34, 156-166 (2010).

[3] L.A. Bendersky, F. Mompiou, J. Alloys Compd. 536S, S171-S174 (2012).

[4] Y.S. Han, J.O. Choi, C.O. Choi, D.G. McCartney, Met. Mater. Int. 10 (1), 27-32 (2004).
[5] T. Gao, Y. Wu, Ch. Li, X. Liu, Mater. Lett. 110, 191-194 (2013).

[6] C. Kammer (Ed), Aluminium Handbook 1: Fundamentals and Materials, 1999 Aluminium-Verlag Marketing \& Kommunikation GmbH, Dusseldorf.

[7] B. Dutta, M. Rettenmayr, Mater. Sci. Eng. A, A283, 218-224 (2000).

[8] A. Griger, V. Stefaniay, J. Mater. Sci. 31, 6645-6652 (1996).

[9] D. Panahi, D.V. Malakhov, M. Gallerneault, P. Marois, Can. Metall. Q. 50 (2), 173-180 (2011).

[10] H. Yang, S. Ji, Z. Fan, Mater. Des. 85, 823-832 (2015).

[11] H. Chen, Q. Chen, Y. Du, J. Bratberg, A. Engstrom, T. Nonferr. Metal. Soc. 24, 2041-2053 (2014).

[12] Q. Zhao, Z. Qian, X. Cui, Y. Wu, X. Liu, J. Alloys Compd. 650, 768-776 (2015) 